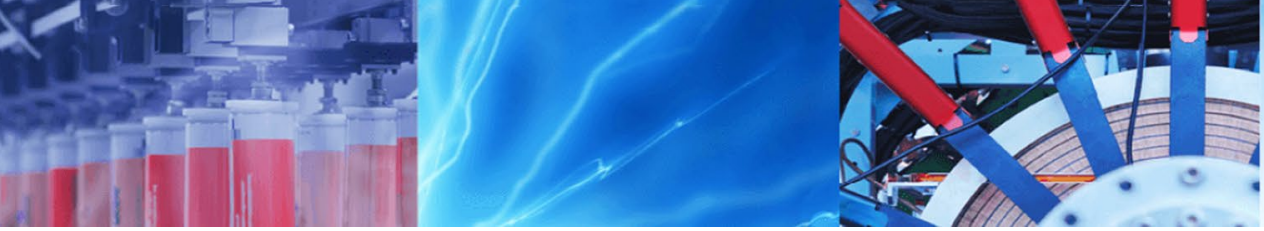

Research Article

\title{
Yield acceleration of reinforced soil slopes using the modified pseudo-dynamic method
}

\author{
Nima Farshidfar ${ }^{1} \cdot$ Amin Keshavarz $^{2}$ (D) Seyyed Mohammad Mirhosseini ${ }^{1}$
}

Received: 27 December 2019 / Accepted: 30 March 2020 / Published online: 15 April 2020

(c) Springer Nature Switzerland AG 2020

\begin{abstract}
This study presents the yield acceleration of reinforced soil slopes using the horizontal slice approach. Yield acceleration plays a key role in calculating the permanent seismic displacement of slopes. The modified pseudo-dynamic method, in conjunction with the equivalent linear site response analysis, is used. Unlike the pseudo-static analysis, the pseudodynamic method takes into account the effects of time and phase difference of waves propagation. The developed computer code is used to compute the yield acceleration. Using the planar and log-spiral slip surfaces, this code considers the distribution of reinforcement layers as uniform and variable spacing. The effect of surcharge pressure is also considered. According to the results, the modified pseudo-dynamic method using the equivalent linear ground response analysis led to more critical results than other methods.
\end{abstract}

Keywords Reinforced soil slopes · Yield acceleration · Pseudo-dynamic · Equivalent linear method · Limit equilibrium . Horizontal slice method

\section{Introduction}

The estimation of permanent displacement of soil structures during an earthquake plays an important role in their proper and optimal design. In addition, yield acceleration is a key parameter in obtaining the permanent displacement of soil slopes using Newmark's sliding block method.

Different numerical methods have been developed in recent years for evaluating the stability of reinforced soil slopes (RSSs). Among these methods are the limit equilibrium method (LEM), limit analysis method, and numerical techniques, including finite element and finite difference methods. Due to its acceptable results and relatively easy analysis mechanism, the LEM has become very popular for slope analysis.

The horizontal slice method (HSM) was first used by Lo and $\mathrm{Xu}[1]$ to compute the stability of the soil slopes, and it was then employed more precisely by Shahgholi et al. [2] to study the stability of the walls. Fakher et al. [3] and Nouri et al. [4] studied the stability of RSSs by developing a new formulation for HSM by assuming the log-spiral slip surface. Azad et al. [5] applied the pseudo-dynamic method into a HSM to investigate the seismic lateral earth pressure of an unreinforced soil retaining walls. Reddy et al. [6] also used the HSM for pseudo-static analysis of reinforced retaining walls subjected to inclined loads.

The pseudo-static (PS) analysis is an approximate and simple technique for seismic analysis of soil structures. The dynamic effects of seismic forces, time, and phase difference of waves are ignored in this method. Many studies have been conducted for the seismic stability of RSSs using the PS method. Bathurst and Cai [7] evaluated the seismic stability of reinforced soil retaining walls using this method. Ling et al. [8] developed a new method for designing RSSs

Amin Keshavarz, keshavarz@pgu.ac.ir; Nima Farshidfar, nima.farshidfar@gmail.com; Seyyed Mohammad Mirhosseini, m-mirhoseini@iau-arak.ac.ir | 'Department of Civil Engineering, Arak Branch, Islamic Azad University, Arak, Iran. ${ }^{2}$ School of Engineering, Persian Gulf University, Bushehr, Iran. 
using the limit equilibrium and PS analyses. Michalowski [9, 10] evaluated the permanent displacement of reinforced and non-reinforced soil slopes under seismic conditions. Several research works have also been conducted for the seismic stability of soil structures using the PS method [3, 4, 11-15]. Vahedifard et al. [16] developed a closed-form solution for calculating the required amount of reinforcement to improve the stability of soil slopes. Their method could also calculate the yield acceleration.

Unlike the PS method, the effects of time, phase difference, and dynamic soil parameters are considered in the pseudo-dynamic (PD) approach. Bellezza $[17,18]$ modified the pseudo-dynamic method by conducting a linear site response analysis of the soil mass to evaluate the seismic active earth pressure on the retaining walls. Using this modified pseudo-dynamic (MPD) method, Pain et al. [19-21] studied, respectively, the rotational stability of the gravity retaining walls, resistant pressure behind the retaining walls, and the interaction between soil and retaining wall under seismic conditions. Chanda et al. [22] and Pain et al. [23] evaluated the stability of RSSs using the limit equilibrium method through MPD analysis. Keshavarz et al. [24] calculated the yield acceleration of RSSs for uniform and non-uniform distribution of reinforcement layers, using the MPD through a limit equilibrium method. Izadi et al. [25] presented the seismic bearing capacity coefficient of strip footings using the PD in conjunction with the LEM. Saha and Ghosh [26] applied MPD to evaluate the seismic bearing capacity of shallow strip footing considering fully log-spiral passive zone. Pain et al. [27] assessed the effects of dynamic soil parameters on the seismic bearing capacity of surface footing by the MPD method. Using the MPD method, Saha and Ghosh [28] calculated the seismic bearing capacity of shallow footing considering the Rayleigh wave along with primary and shear waves velocity.

Among the advantages of the MPD method against the PS method are: (1) considering the effects of time, phase difference, and logical amplification of seismic forces, (2) satisfying boundary conditions (zero stress on the ground surface), and (3) the ability of investigating the effects of dynamic parameters of soil, such as damping ratio and shear wave velocity. However, this method utilizes the linear site response analysis. Therefore, the dynamic properties of the soil, such as shear modulus and damping ratio, are constant and independent of the time, depth, and shear strain. This shortcoming can be overcome by using the equivalent linear site response analysis through the MPD method, which is conducted in this study.

In this paper, the yield acceleration of the RSSs is calculated using the HSM as $5 N-1$ formulation, in which the equilibrium equations of all vertical and horizontal forces, as well as the moment, are satisfied. The yield acceleration is calculated using the PS, MPD method using the linear site response analysis (MPD-L), and MPD method using the equivalent-linear site response analysis (MPD-EL). The effect of soil strain variations on the soil dynamics parameters is considered in the MPD-EL approach. The vertical spacing between the reinforcement layers is assumed to be uniform and variable. Furthermore, the effect of surcharge pressure on the yield acceleration is evaluated.

\section{Theory}

Figure $1 a, b$ shows an RSS with uniform and variable distribution of reinforcements, respectively. Equations (1) and (2) describe the depth $Y_{r, j}$ of $j$ th reinforcement layer from the top of the slope for both the uniform and variable distributions, relatively [10]. In these equations, $n$ denotes the total number of reinforcements.

$Y_{r, j}=(j-0.5) \frac{H}{n} ; j=1,2, \ldots, n$

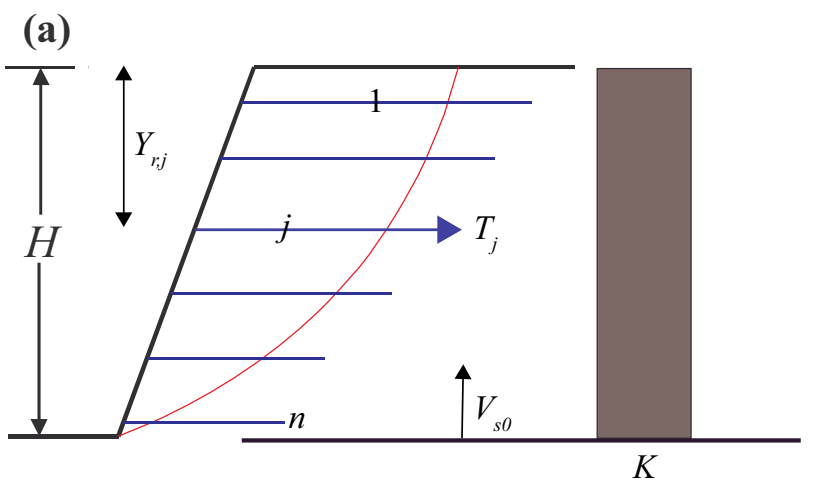

(b)

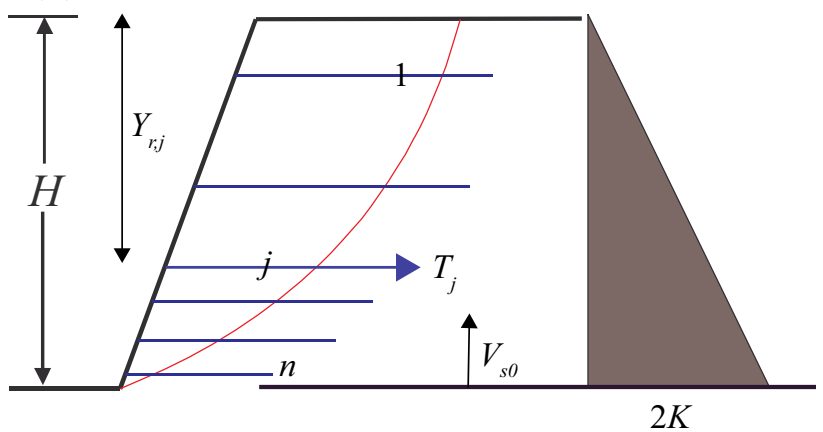

Fig. 1 Distribution of reinforcements; a uniform, and $\mathbf{b}$ variable spacing 
$Y_{r, j}=\frac{2}{3} n H\left[\sqrt{\left(\frac{j}{n}\right)^{3}}-\sqrt{\left(\frac{j-1}{n}\right)^{3}}\right] ; j=1,2, \ldots, n$

The reinforcements force is denoted as the dimensionless parameters $K[8]$ :

$K=\frac{\sum_{j=1}^{n} T_{j}}{0.5 \gamma H^{2}}$

where $\gamma$ is the soil unit weight, $H$ is the slope height, and $T_{j}$ represents the mobilized tensile force of the $j$ th reinforcement layer. The approximate value of $T_{j}$ is obtained as:

$T_{j}=K \gamma Y_{r, j} D_{r, j}$

where $D_{r, j}$ is the distance between the two reinforcing layers (Fig. 2a). In general, $T_{j}$ is the minimum values of $T_{\mathrm{u}}$ and $T_{\mathrm{p}}$, where $T_{\mathrm{u}}$ is the tensile strength of the reinforcement, and $T_{p}$ is the pull-out force obtained from the following equation:

(a)

$$
\mathrm{O}\left(x_{0}, y_{0}\right)
$$

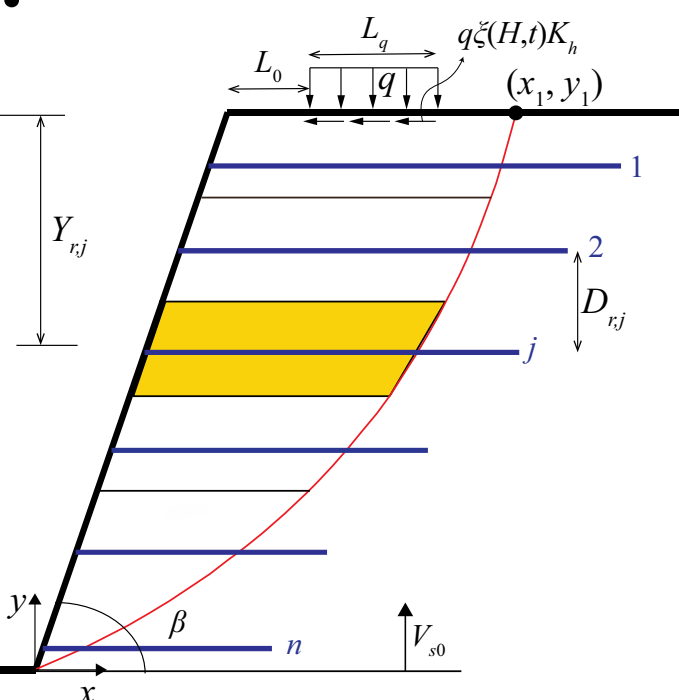

(b)

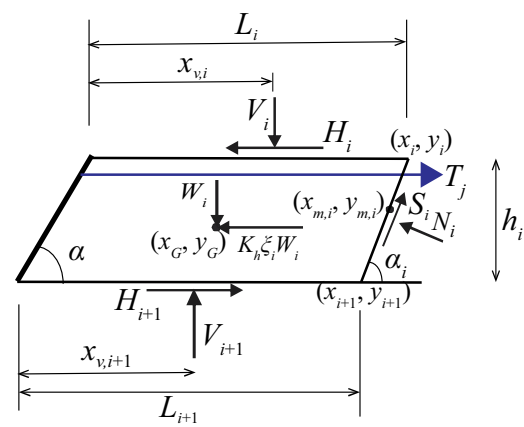

Fig. 2 a Geometry of the problem; $\mathbf{b}$ forces acting on a slice (a)

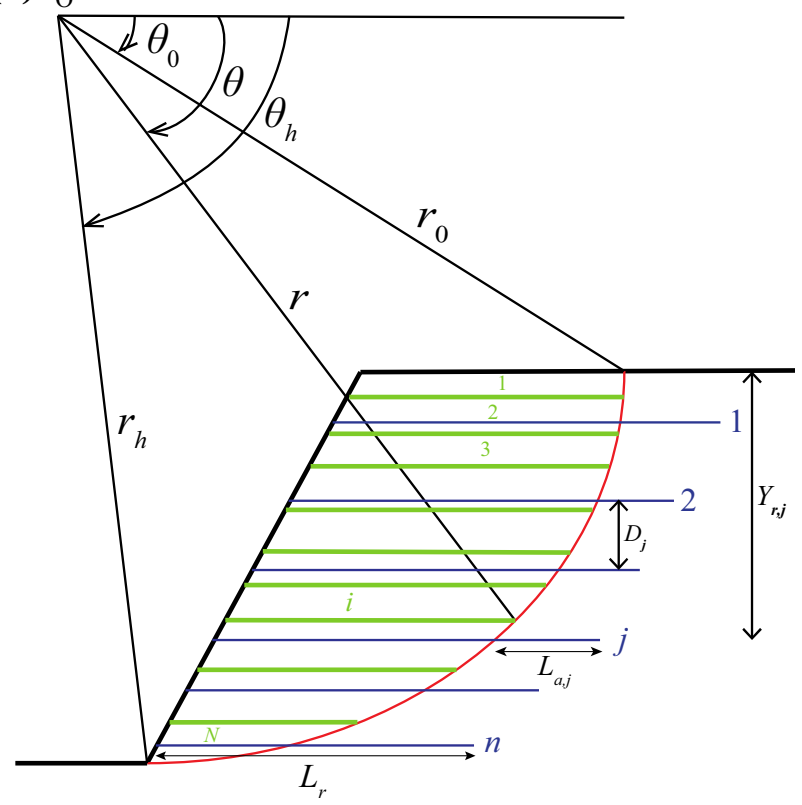

(b)

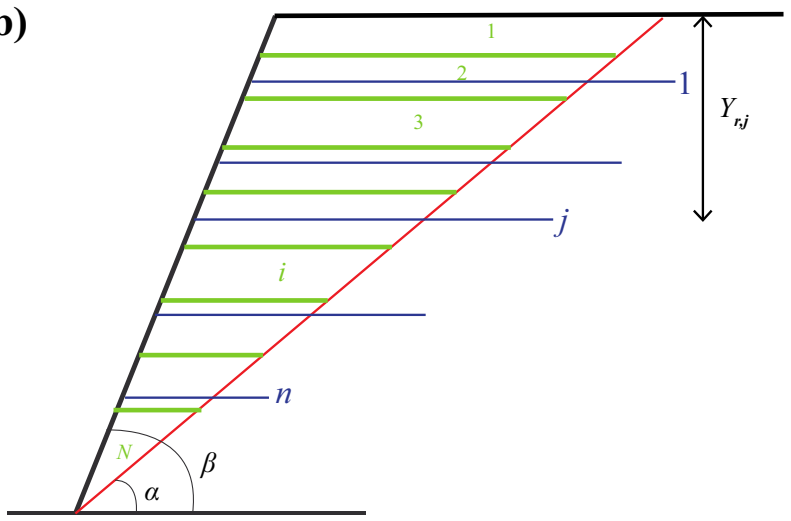

Fig. 3 Different failure surfaces: a log-spiral slip surface, b planar slip surface

$T_{\mathrm{p}}=2 \gamma Y_{\mathrm{r}, j} L_{\mathrm{a}, j} \mu \tan \phi$

where $\phi$ is the soil friction angle, $L_{a, j}$ is the anchorage length of the $j$ th reinforcement (Fig. 3a), and $\mu$ is the pullout coefficient of the soil reinforcement. The parameter $\mu$ typically ranges from 0.7 to 1 .

In the HSM, the failure wedge is divided into a series of horizontal slices parallel to the reinforcement (Fig. 2a). Equations (6), (7), and (8) are, respectively, the equilibrium equation of forces along the vertical and horizontal directions, and moment of forces about point $\mathrm{O}$.

$V_{i+1}-V_{i}-W_{i}+S_{i} \sin \alpha_{i}+N_{i} \cos \alpha_{i}=0$

$T_{j}+S_{i} \cos \alpha_{i}-N_{i} \sin \alpha_{i}-\xi_{i} K_{h} W_{i}+H_{i+1}-H_{i}=0$ 


$$
\begin{aligned}
& V_{i+1}\left(x_{i+1}-x_{0}-L_{i+1}-x_{V, i+1}\right)-V_{i}\left(x_{i}-x_{0}-L_{i}-x_{v, i}\right) \\
& +T_{j}\left(y_{0}-H+Y_{r, j}\right)+H_{i+1}\left(y_{0}-y_{i+1}\right)-H_{i}\left(y_{0}-y_{i}\right) \\
& +\left(S_{i} \sin \alpha_{i}+N_{i} \cos \alpha_{i}\right)\left(x_{m, i}-x_{0}\right)+\left(S_{i} \cos \alpha_{i}-N_{i} \sin \alpha_{i}\right) \\
& \quad\left(y_{0}-y_{m, i}\right)-W_{i}\left(x_{G, i}-x_{0}\right)-\xi_{i} K_{\mathrm{h}} W_{i}\left(y_{0}-y_{G, i}\right)=0
\end{aligned}
$$

The equations and unknowns of the problem are presented in Table 1. According to Table 1, $5 N-1$ equations and unknowns are obtained, where $N$ is the total number of horizontal slices.

Figure $2 \mathrm{~b}$ shows all forces and parameters acted on a horizontal slice. In this figure, $H_{i}$ and $V_{i}$ denote, respectively, the horizontal and vertical interslice forces of the upper surface of the slice, $S_{i}$ and $N_{i}$ are, respectively, the tangential and normal forces exerted on the failure surface, $W_{i}$ is the slice weight, $x_{v, i}$ is the distance between the slope face and the point of application of $V_{i}, a_{i}$ is the angle of sliding surface of the $i$ th slice to the horizon, and $X_{\mathrm{G}, i}$ and $Y_{\mathrm{G}, i}$ are the coordinates of the center of gravity of the slice.

The relationship between the horizontal and vertical interslice forces is [29]:

$H_{i}=\lambda f_{i} V_{i}$

where $\lambda$ is an unknown scalar parameter which is assumed to be the same for all slices, and $f_{i}$ is an arbitrary function which is assumed equal to 1 in this study. The relationship between tangential and normal forces $\left(S_{i}\right.$ and $\left.N_{i}\right)$ is:

$S_{i}=\frac{N_{i} \tan \phi}{F_{\mathrm{s}}}$

where $F_{s}$ denotes the safety factor.

Table 1 Number of unknowns and equations in the formulation [24]

\begin{tabular}{ll}
\hline Unknowns & Number \\
\hline Normal force of each slice, $N_{i}$ & $N$ \\
Shear force of each slice, $S_{i}$ & $N$ \\
Horizontal interslice force, $H_{i}$ & $N-1$ \\
Vertical interslice force, $V_{i}$ & $N-1$ \\
Location of vertical interslice force, $x_{v, i}$ & $N-1$ \\
Morgenstern and Price factor, $\lambda$ & 1 \\
Seismic acceleration coefficient, $K_{\mathrm{h}}$ & 1 \\
Sum & $5 N-1$ \\
Equations & $N u m b e r$ \\
$\sum F_{x}=0$, each slice & $N$ \\
$\sum F_{y}=0$, each slice & $N$ \\
$\sum M_{o}=0$, each slice & $N$ \\
$S_{i}=\frac{N_{i} \text { tan }}{F_{s}}$, each slice & $N$ \\
Morgenstern and Price assumption, $H_{i}=\lambda f_{i} V_{i}$ & $N-1$ \\
Sum & $5 N-1$ \\
\hline
\end{tabular}

The horizontal acceleration coefficient in the base of the slope is considered by the parameter $K_{\mathrm{h}}$. The horizontal acceleration coefficient can change based on the value of $\xi_{i}$ in different depths and times.

By solving Eqs. (6)-(10) simultaneously, two equations for each slice are obtained as presented in Eq. (11).

$\left\{\begin{array}{l}\left(\lambda f_{i+1}-A_{1}\right) V_{i+1}+\left(A_{1}-\lambda f_{i}\right) v_{i}-\xi_{i} K_{\mathrm{h}} W_{i}+A_{2}=0 \\ \left(A_{3}+x_{v, i+1}+\lambda f_{i+1}\left(y_{0}-y_{i+1}\right)\right) v_{i+1}-\left(A_{4}+x_{v, i}+\lambda f_{i}\left(y_{0}-y_{i}\right)\right) v_{i} \\ \quad-\xi_{i} K_{\mathrm{h}} W_{i}\left(y_{0}-y_{\mathrm{G}, i}\right)+A_{5}=0\end{array}\right.$

where

$$
\begin{aligned}
& A_{1}=m_{i}\left(\frac{\tan \phi}{F_{\mathrm{s}}} \cos \alpha_{i}-\sin \alpha_{i}\right) \\
& A_{2}=A_{1} W_{i}+T_{j} \\
& A_{3}=x_{i+1}-x_{0}-L_{i+1}-m_{i} B_{i} \\
& A_{4}=x_{i}-x_{0}-L_{i}-m_{i} B_{i} \\
& A_{5}=m_{i} A_{i} B_{i}-W_{i}\left(x_{G, i}-x_{0}\right)+T_{j}\left(y_{0}-Y_{r, j}-H\right)
\end{aligned}
$$

and

$$
\begin{aligned}
m_{i} & =\frac{1}{\cos \alpha_{i}+\frac{\tan \phi}{F_{\mathrm{s}}} \sin \alpha_{i}} \\
B_{i} & =\frac{x_{m, i}-x_{0}}{m_{i}}+\left(\frac{\tan \phi}{F_{\mathrm{s}}} \cos \alpha_{i}-\sin \alpha_{i}\right)\left(y_{0}-y_{m, i}\right)
\end{aligned}
$$

In this way, $5 N-1$ equations and unknowns in Table 1 reduce to $2 \mathrm{~N}$ equations and unknowns. The system of nonlinear equations can be written in the following form:

$[F]\{X\}=0$

where $\{X\}$ is the unknown vector which is equal to:

$$
\{X\}=\left[V_{2}, V_{3}, \ldots, V_{N}, x_{V, 1}, x_{v, 2}, \ldots, x_{v, N}, \lambda, K_{h}\right]^{\top}
$$

and $[F]$ is the coefficient matrix. In the present study, the Newton-Raphson technique is employed to solve Eq. (14) and the main unknown is $K_{\mathrm{h}}$, which will be equal to $K_{\mathrm{y}}$ as the yield acceleration.

In Eq. (11), the values of $v_{i+1}$ and $x_{v, i+1}$ for the last slice (bottom of the slope; $i=N$ ) are zero. Furthermore, the values of $V_{i}, H_{i}$ and $x_{v, i}$ for the first slice (at the ground surface; $i=1$ ) are defined as (see Fig. 2):

$$
\begin{aligned}
& \left\{\text { if } x_{1}<\left(H \cot \beta+L_{0}\right) \text { then } V_{1}=0 ; x_{v, 1}=0 ; H_{1}=0\right. \\
& \left\{\begin{array}{l}
\text { if } x_{1}>\left(H \cot \beta+L_{0}+L_{\mathrm{q}}\right) \text { then } V_{1}=q L_{\mathrm{q}} ; \\
x_{v, 1}=L_{0}+0.5 L_{\mathrm{q}} ; H_{1}=q L_{\mathrm{q}} \xi(H, t) K_{\mathrm{h}}
\end{array}\right. \\
& \left\{\begin{array}{l}
\text { if }\left(H \cot \beta+L_{0}\right)<x_{1}<\left(H \cot \beta+L_{0}+L_{\mathrm{q}}\right) \text { then } \\
V_{1}=q\left(x_{1}-H \cot \beta-L_{0}\right) ; \\
x_{v, 1}=0.5\left(x_{1}-H \cot \beta+L_{0}\right) ; H_{1}=q\left(x_{1}-H \cot \beta-L_{0}\right) \xi(H, t) K_{\mathrm{h}}
\end{array}\right.
\end{aligned}
$$


In the PS method, the earthquake acceleration coefficient is considered to be constant in depth and is not a function of time $\left(\xi_{i}=1\right)$; whereas the acceleration is a function of depth and time in the pseudodynamic methods. Assuming the harmonic acceleration $a_{\mathrm{h}}(0, t)=K_{\mathrm{h}} g \exp (i \omega t)$ exerting on the base of the slope, acceleration of each slice can be determined as $a_{\mathrm{h}}(y, t)=K_{\mathrm{h}} g \xi(y, t)$, where $\omega$ is the angular frequency, and $g$ is the gravity acceleration.

In the MPD method, $\xi(y, t)$ is expressed as:

$\xi(y, t)=\frac{1}{C^{2}+S^{2}}\left[\left(C C_{y}+S S_{y}\right) \cos (t)+\left(S C_{y}-C S_{y}\right) \sin (t)\right]$ damping ratio and normalized shear modulus equations proposed by Seed and Idriss [30] are used for the equivalent linear analysis [23]:

$\frac{G}{G_{0}}=\frac{1}{1+8\left(\frac{\gamma_{s}}{0.37}\right)^{0.92}}$

$D(\%)=28\left(1-\exp \left(-2.5 \gamma_{\mathrm{s}}^{0.51}\right)\right)$

where $\gamma_{s}$ is the percentage shear strain, and $G_{0}$ is the low strain shear modulus $\left(G_{0}=\rho V_{s 0}^{2}\right)$, where $V_{\mathrm{s} 0}$ is the shear wave velocity on the base of slope at the initial time. The value of $\gamma_{s}$ can be presented as [23]:

$$
\begin{aligned}
\gamma_{s}(z, t) & =\frac{\partial u(y, t)}{\partial y} \\
& =\frac{-k_{\mathrm{h}} g}{\omega^{2} H\left(C^{2}+S^{2}\right)}\left[\begin{array}{r}
\left(\begin{array}{c}
y_{2} \cos \left(y_{1} H_{n}\right) \sinh \left(y_{2} H_{n}\right) \cos \left(y_{1}\right) \cosh \left(y_{2}\right)-y_{1} \cosh \left(y_{2} H_{n}\right) \sin \left(y_{1} H_{n}\right) \cos \left(y_{1}\right) \cosh \left(y_{2}\right) \\
+y_{1} \cos \left(y_{1} H_{n}\right) \sinh \left(y_{2} H_{n}\right) \sin \left(y_{1}\right) \sinh \left(y_{2}\right)+y_{2} \cosh \left(y_{2} H_{n}\right) \sin \left(y_{1} H_{n}\right) \sin \left(y_{1}\right) \sinh \left(y_{2}\right)
\end{array}\right) \cos (\omega t) \\
+\left(\begin{array}{r}
y_{1} \cosh \left(y_{2} H_{n}\right) \sin \left(y_{1} H_{n}\right) \sin \left(y_{1}\right) \sinh \left(y_{2}\right)-y_{2} \cos \left(y_{1} H_{n}\right) \sinh \left(y_{2} H_{n}\right) \sin \left(y_{1}\right) \sinh \left(y_{2}\right) \\
+y_{1} \cos \left(y_{1} H_{n}\right) \sinh \left(y_{2} H_{n}\right) \cos \left(y_{1}\right) \cosh \left(y_{2}\right)+y_{2} \cosh \left(y_{2} H_{n}\right) \sin \left(y_{1} H_{n}\right) \cos \left(y_{1}\right) \cosh \left(y_{2}\right)
\end{array}\right) \sin (\omega t)
\end{array}\right]
\end{aligned}
$$

where

$$
\begin{aligned}
C & =\cos \left(y_{1}\right) \cosh \left(y_{2}\right) \\
S & =-\sin \left(y_{1}\right) \sinh \left(y_{2}\right) \\
C_{y} & =\cos \left(y_{1} H_{n}\right) \cosh \left(y_{2} H_{n}\right) \\
S_{y} & =-\sin \left(y_{1} H_{n}\right) \sinh \left(y_{2} H_{n}\right)
\end{aligned}
$$

and

$$
\begin{aligned}
& y_{1}=\frac{\omega H}{V_{s}} \sqrt{\frac{\sqrt{1+4 D^{2}}+1}{2\left(1+4 D^{2}\right)}} \\
& y_{2}=-\frac{\omega H}{V_{s}} \sqrt{\frac{\sqrt{1+4 D^{2}}-1}{2\left(1+4 D^{2}\right)}} \\
& H_{n}=\frac{H-y_{G, i}}{H}
\end{aligned}
$$

In these equations, $V_{s}=\sqrt{G / \rho}$ is the shear wave velocity, $G$ is the secant shear modulus, $\rho$ is the soil density, and $D$ represents the soil damping ratio. Equation (17) is obtained based on the 1Dsite response analysis.

In the MPD-L method, $D$ and $V_{s}$ are assumed constant for all slices $\left(V_{s}=V_{s 0}\right)$. However, in the MPD-EL method, the dynamic parameters of the soil, such as damping ratio and shear wave velocity, are not constant and are functions of time, depth, and shear strain. Unlike the study of Keshavarz et al. [24], the equivalent linear analysis is used in the current study to analyze the site response. The
The equivalent linear analysis of each layer at a given time is conducted as follows:

1. Calculate $G_{0}=\rho V_{s 0}^{2}$.

2. Assume initial values for $G / G_{0}$ and $D$ for a low shear strain $\left(G / G_{0}=1\right.$ and $\left.D=0\right)$.

3. Calculate shear strain using Eq. (22).

4. Using Eqs. (20) and (21), compute $G / G_{0}$ and $D$ using the shear strain value obtained in the previous step.

5. Repeat steps 3 and 4 until the relative error of $G / G_{0}$ and $D$ between the last two tries become lower than $5 \%$.

6. Calculate the shear wave velocity using the shear modulus obtained from the previous step.

7. Using Eq. (17) and the shear wave velocity and damping ratio obtained in the previous step, compute the horizontal acceleration coefficient.

The formulation used in this study is capable of analyzing any type of the sliding surface through the HSM. Figure $3 a$ shows a log-spiral sliding surface, which is described as:

$$
\begin{aligned}
& r=r_{0} \exp \left[\left(\theta-\theta_{0}\right) \tan \phi\right] \\
& r_{0}=\frac{H}{\sin \theta_{\mathrm{h}} \exp \left[\left(\theta_{h}-\theta_{0}\right) \tan \phi\right]-\sin \theta_{0}} ; \theta_{0} \leq \theta_{\mathrm{h}} \leq \frac{\pi}{2}+\phi
\end{aligned}
$$


Having the values of $H$ and $\phi$, two parameters of $\theta_{0}$ and $\theta_{\mathrm{h}}$ are required for forming a log-spiral sliding surface. Figure $3 \mathrm{~b}$ shows a planar sliding surface. To form this planar sliding surface, only the angle of sliding surface $(a)$ suffices.
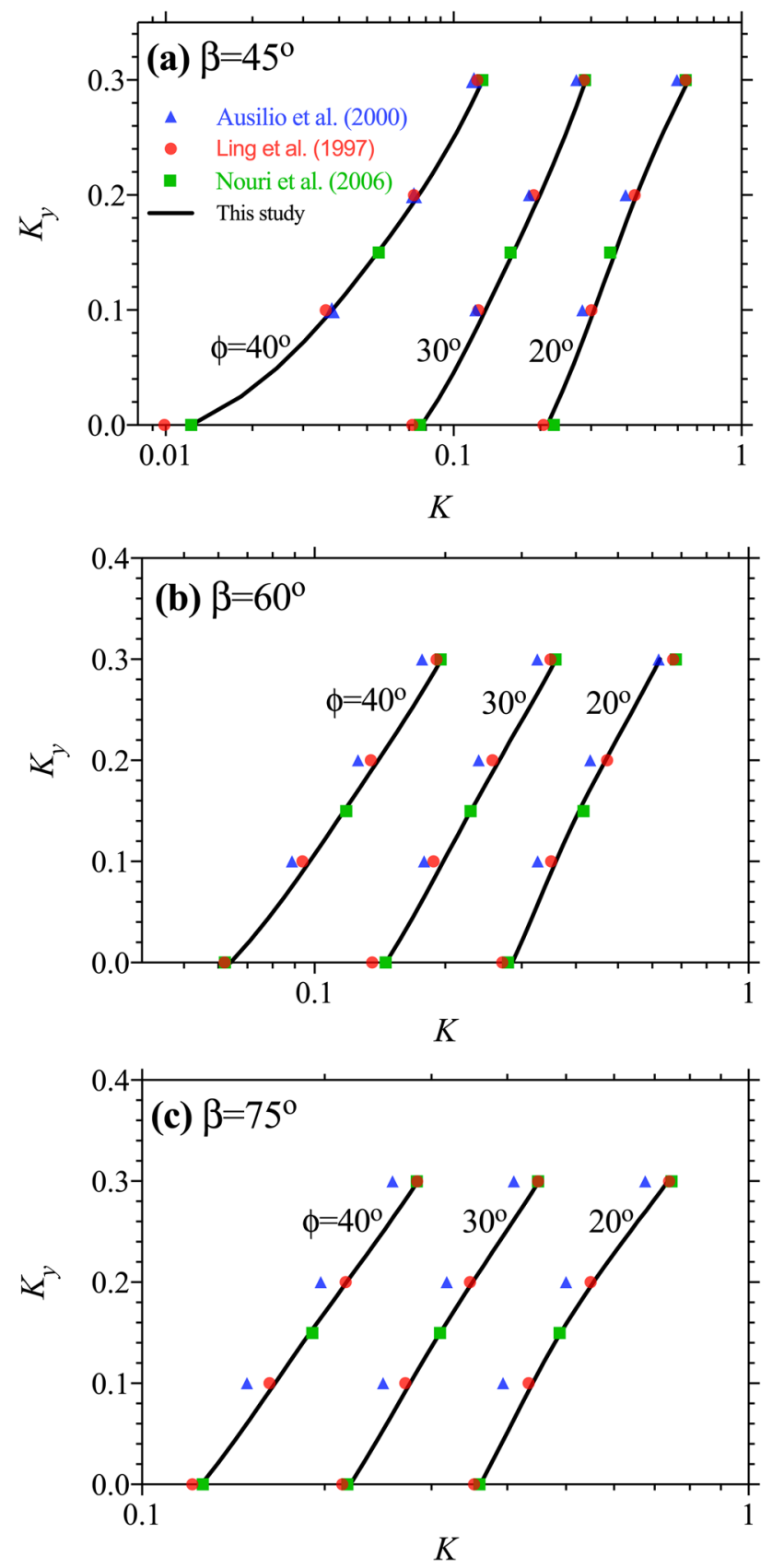

Fig. 4 For $T_{u}<T_{p}$, comparison between the results obtained from PS method of the present study and those of others for: $\mathbf{a} \beta=45^{\circ}, \mathbf{b}$ $\beta=60^{\circ}, \mathbf{c} \beta=75^{\circ}$

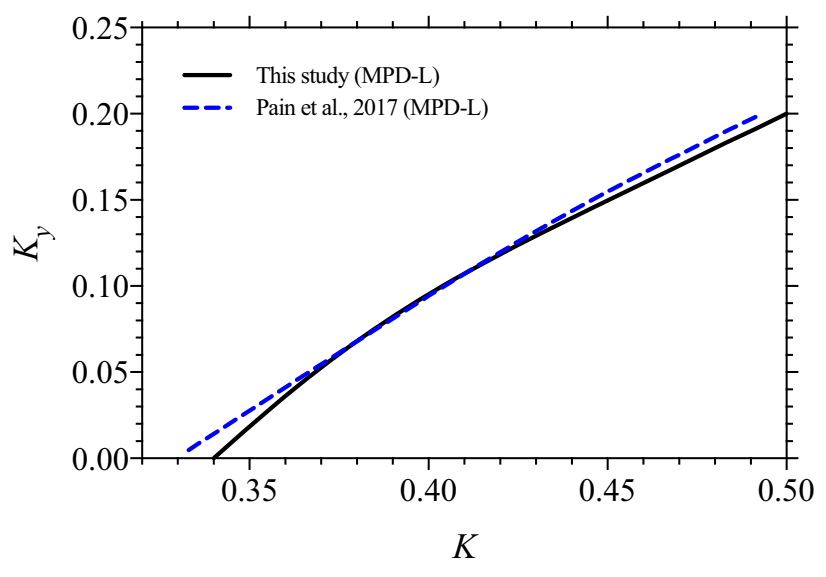

Fig. 5 For $\beta=90^{\circ}, D=10 \%$ and $\phi=30^{\circ}$, the values of $K_{y}$ versus $K$ obtained MPD-L method of the present study compared with those of Pain et al. [23]

\section{Results and discussion}

A MATLAB code was developed using the method described in the previous sections. The pattern search optimization algorithm in MATLAB was used to calculate the optimal values of desirable parameters. To calculate the yield acceleration using the pseudo-dynamic method, the optimum values of $\theta_{0}, \theta_{\mathrm{h}}$, and $t$ for the logspiral sliding surface, and $a$ and $t$ for the planar sliding surface should be determined.

In the analysis of RSSs using the mentioned method, each sliding surface may involve the reinforced zone or extend within and beyond the reinforced zone. In the case where the length of the reinforcements is limited to an assumed length $L_{r}$, many slip surfaces are created during the optimization procedure. Some of them involve the reinforced zone, and others extend within and beyond the reinforced zone. The number of the horizontal slices $(N)$ must be large enough such that no slice has two or more reinforcement layers. Unlike otherwise indicated, it is assumed that $H=5 \mathrm{~m}, \gamma=18 \mathrm{kN} / \mathrm{m}^{3}, \mu=0.8$, $n=10$, and $N=35$.

Briefly, the results include even parts: (1) Figs. 4, 5 and Table 2 compare the values of yield acceleration obtained

Table 2 Comparison between the results of this study (PS method) and those of Vahedifard et al. [16] $\left(\beta=70^{\circ}, K=0.32\right.$, and $\left.T_{\mathrm{u}}>T_{\mathrm{p}}\right)$

\begin{tabular}{llllll}
\hline$\phi\left(^{\circ}\right)$ & \multicolumn{2}{l}{ This study } & & & \multicolumn{2}{l}{ Vahedifard et al. [16] } \\
\cline { 2 - 3 } \cline { 5 - 6 } & $\begin{array}{l}\text { Uniform } \\
\text { spacing }\end{array}$ & $\begin{array}{l}\text { Variable } \\
\text { spacing }\end{array}$ & & Uniform spacing & Variable spacing \\
\hline 30 & 0.2 & 0.22 & 0.17 & 0.2 \\
40 & 0.38 & 0.4 & 0.379 & 0.384 \\
\hline
\end{tabular}



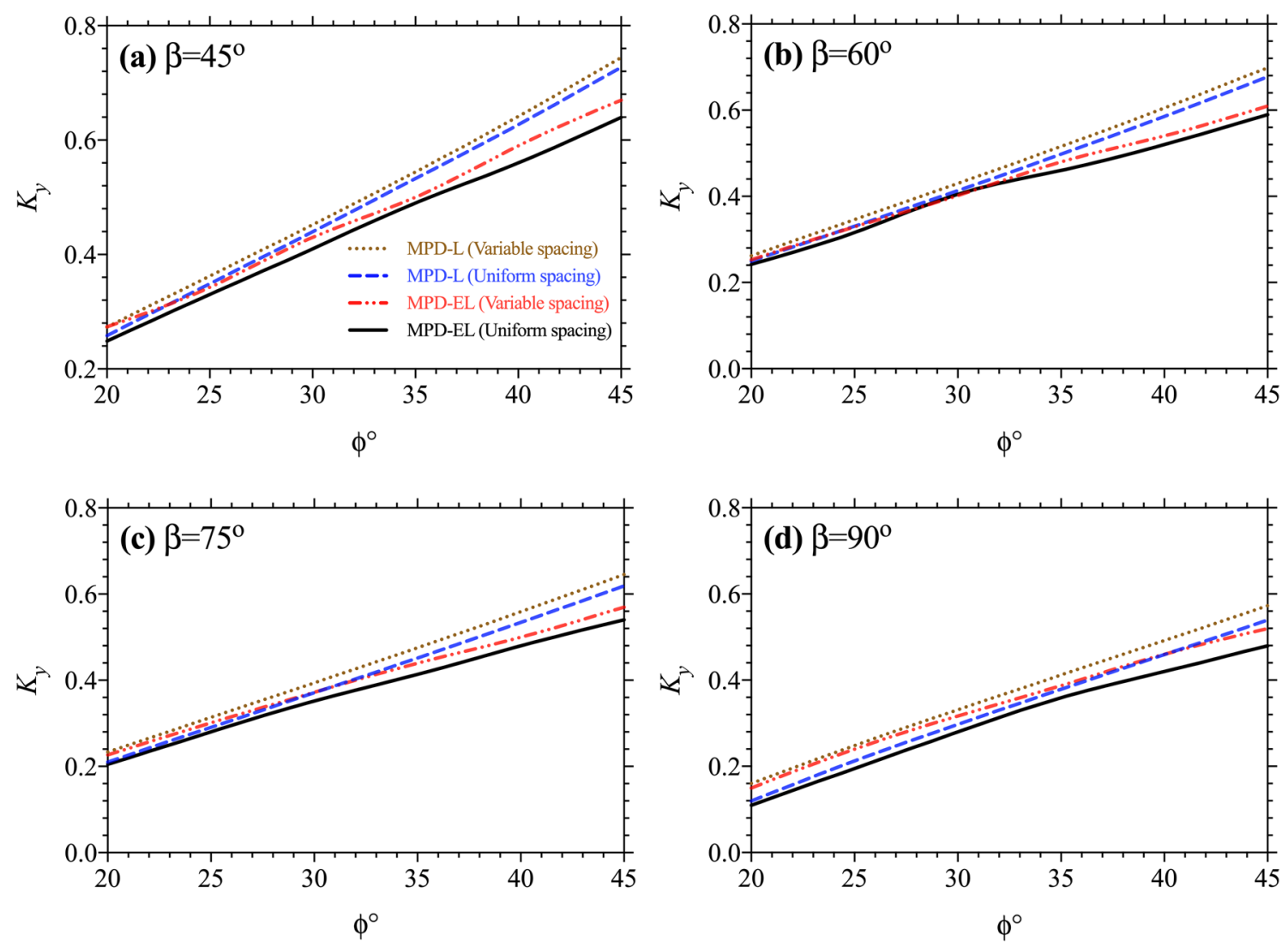

Fig. 6 For $D=10 \%$ (in MPD-L method), $K=0.6, \omega H / V_{s 0}=0.475, K=0.6$, and $T_{u}<T_{\mathrm{p}}$; the variation of the yield acceleration versus $\phi$ assuming uniform and variable spacing for the MPD-L and MPD-EL methods: $\mathbf{a} \beta=45^{\circ} ; \mathbf{b} \beta=60^{\circ} ; \mathbf{c} \beta=75^{\circ}$; and $\mathbf{d} \beta=90^{\circ}$

from this study, and those of other research works using the PS and MPD method, (2) Figs. 6 and 7 show the effect of site response analysis using the MPD method for different values of soil friction angles and reinforcement forces considering planar and log-spiral slip surfaces, (3) Fig. 8 examines the effect of the normalized frequency using the MPD method considering both linear and equivalent linear site response analyses, (4) Fig. 9 shows the effects of the applied method on the yield acceleration assuming the constant length of reinforcements, (5) the effects of the different approaches on the variation of dynamic soil parameters along soil depth are shown in Fig. 10, (6) Fig. 11 investigates the effects of reinforcements distribution on the values of yield acceleration using different methods, and (7) the effects of surcharge pressures on the yield acceleration are investigated in Fig. 12.
Figure 4 compares the yield acceleration obtained from this study and those of Ausilioet al. [11], Ling et al. [8], and Nouri et al. [4] using the PS method for different values of dimensionless reinforcement force $(K)$, slope angle, and soil friction angle. Results in this figure were obtained for $T_{\mathrm{u}}<T_{\mathrm{p}}$ and based on the log-spiral sliding surfaces. As seen, the obtained results of Ausilioet al. [11] are relatively larger than the others especially for a higher values of slope angle. Also, the results of this study are very close to those of Ling et al. [8] and Nouri et al. [4] using the PS method. This figure indicates that the yield acceleration obtained by the PS method increases with increasing the soil friction angle and dimensionless reinforcement forces $(K)$.

Table 2 compares the results of this study and those of Vahedifard et al. [16] using the PS method for a soil slope with an angle of $70^{\circ}$. Results in this table are obtained 

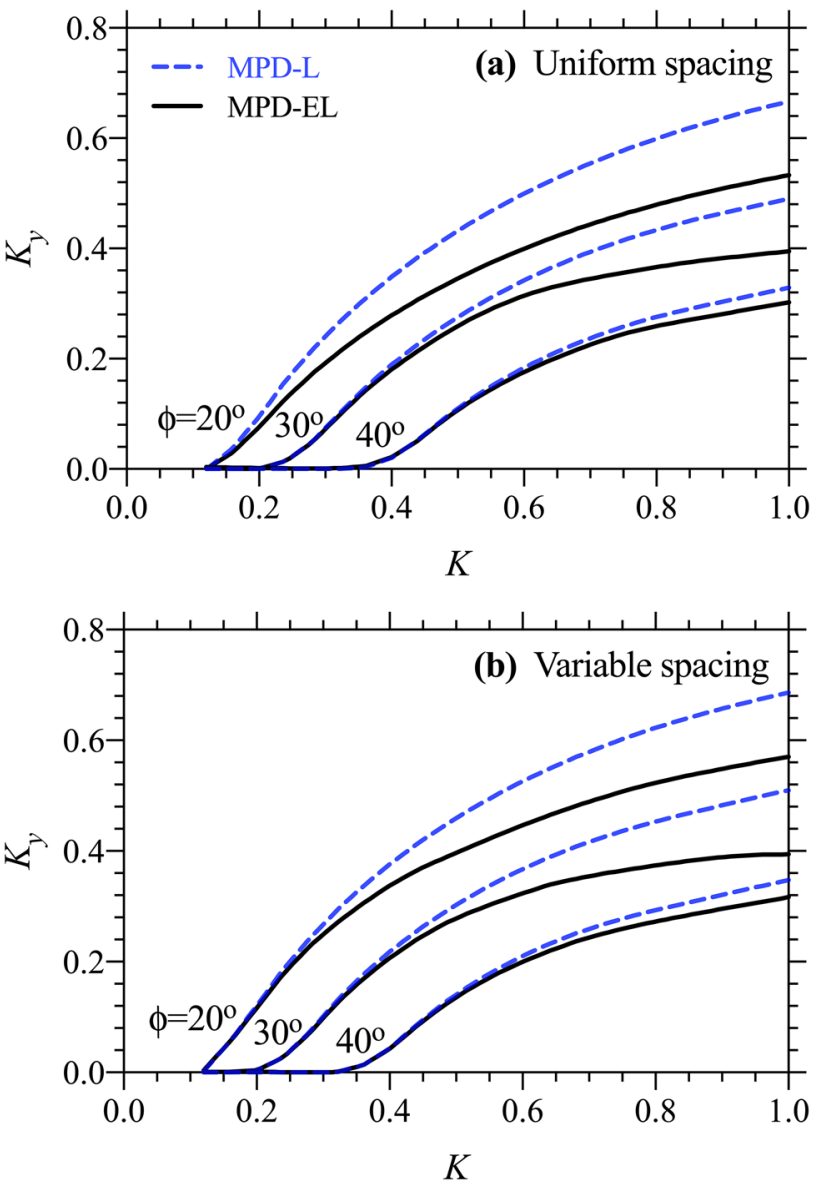

Fig. 7 For $D=20 \%$ (in MPD-L method), $\omega H / V_{s 0}=0.55, \beta=80^{\circ}$, and $T_{\mathrm{u}}<T_{\mathrm{p}}$; the variation of $K_{\mathrm{y}}$ versus $K$ for $\mathbf{a}$ uniform, and $\mathbf{b}$ variable spacing of the reinforcements

assuming $K=0.32, T_{\mathrm{u}}<T_{\mathrm{p}}$, log-spiral sliding surface, and both the uniform and variable spacing of reinforcements. Table 2 shows that the yield accelerations of Vahedifard et al. [16] are relatively more conservative than those of the present study. Also, it can be concluded that the nonuniform distribution of reinforcement layers results greater yield acceleration than the uniform distribution. Table 2 illustrates that very close results are obtained using a similar seismic analysis and log-spiral slip surface.

The yield acceleration values obtained from this study and those of Pain et al. [23] are also compared in Fig. 5 using the MPD-L method for different values of $K$. The
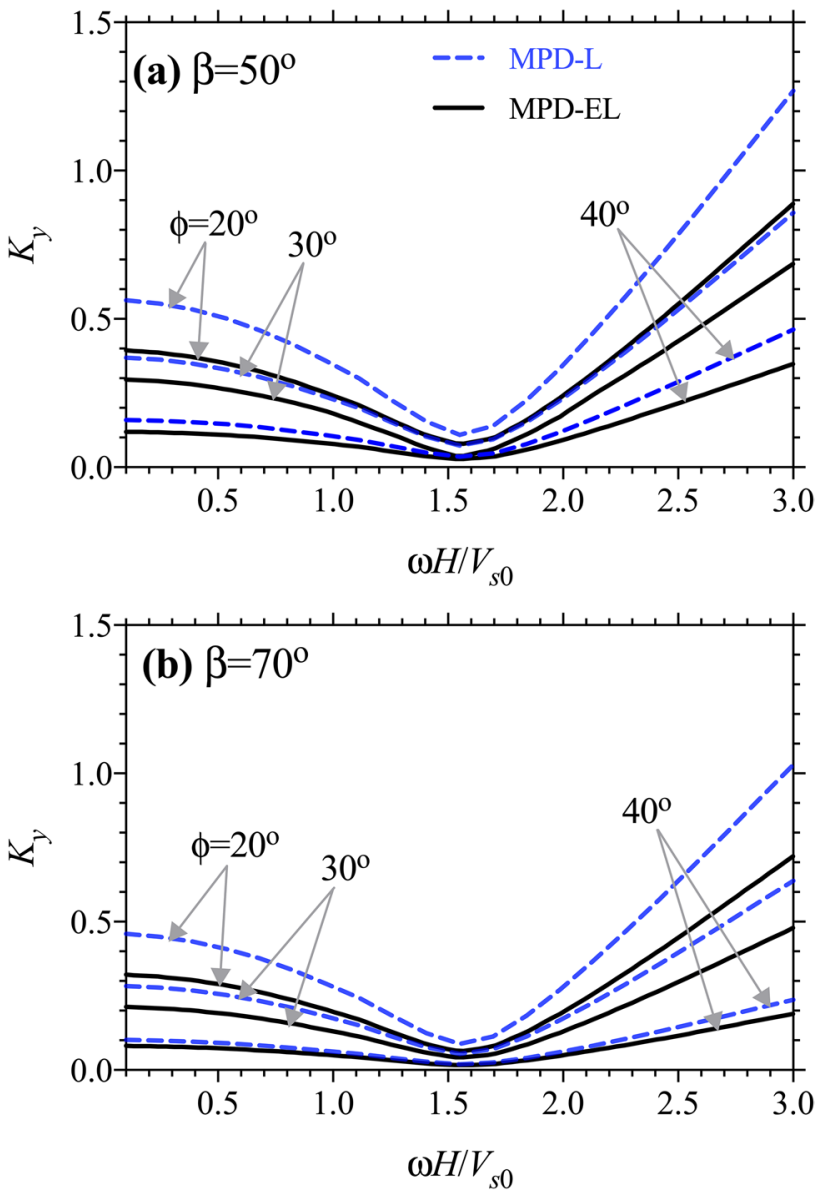

Fig. 8 For $D=10 \%$ (in MPD-L method), $K=0.4, T_{\mathrm{u}}<T_{\mathrm{p}}$, log-spiral slip surface, and uniform spacing of reinforcements, the variation of $K_{\mathrm{y}}$ versus $\omega H / V_{\mathrm{s} 0}$ for MPD-L and MPD-EL methods: $\mathbf{a} \beta=50^{\circ}$ and $\mathbf{b}$ $\beta=70^{\circ}$

results in Fig. 5 are calculated for a 90-degree slope angle assuming the log-spiral slip surface. The normalized frequency and soil damping ratio are considered $\omega H / V_{s}=0.52$ and $10 \%$, respectively. As can be seen, close results are obtained from both studies using the MPD-L method.

Figure 6 shows the yield acceleration obtained from the MPD method based on the linear and equivalent linear site response analysis for $D=10 \%$ (in MPD-L method), $K=0.6$, and $\omega H / V_{\mathrm{s} 0}=0.475$. The results presented in Fig. 6 are obtained based on both the uniform and non-uniform distribution of reinforcements, and the failure surface is assumed log-spiral. Figure 6 shows that the MPD-EL 

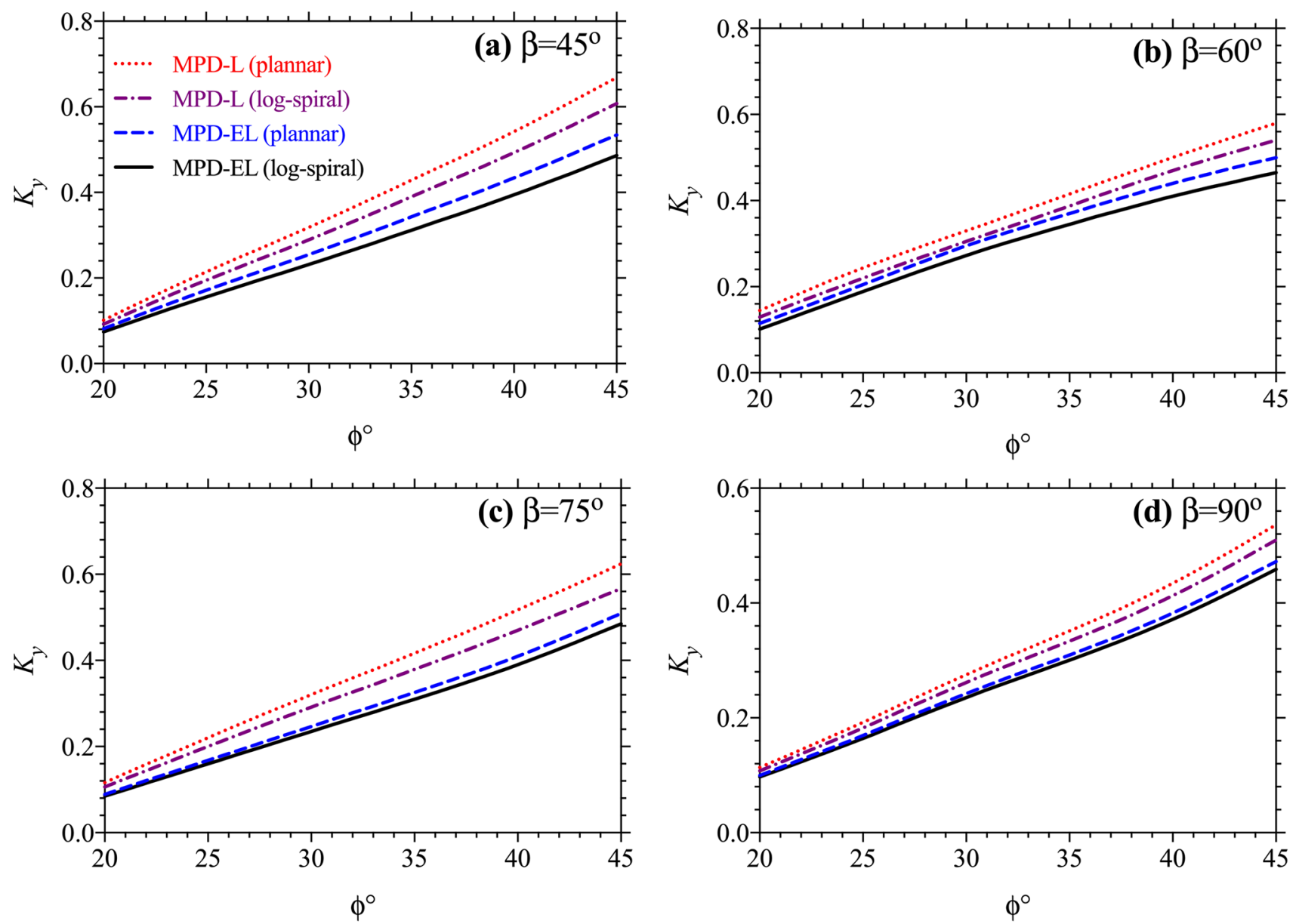

Fig. 9 For $L_{\mathrm{r}}=5 \mathrm{~m}, T_{\mathrm{u}}=25 \mathrm{kN} / \mathrm{m}, \omega H / V_{\mathrm{s} 0}=0.5, n=10$, uniform spacing of reinforcements, and both the log-spiral and planar slip surface; the variations in the $K_{\mathrm{y}}$ versus $\phi$ obtained from MPD-L and MPD-EL methods for: $\mathbf{a} \beta=45^{\circ} ; \mathbf{b} \beta=60^{\circ} ; \mathbf{c} \beta=75^{\circ} ;$ and $\mathbf{d} \beta=90^{\circ}$

method leads to more conservative results as compared to the MPD-L method. According to this figure, the use of non-uniform reinforcements leads to a higher value of the yield acceleration.

Figure 7 illustrates the effect of reinforcement forces $(K)$ on the values of the yield acceleration for different soil friction angles by assuming $D=20 \%$ (in MPD-L method), $\omega H / V_{s 0}=0.55$, and $\beta=80^{\circ}$. Results in Fig. 7 are for both the uniform and non-uniform distribution of reinforcements, and log-spiral sliding surface. According to this figure, all results follow a similar trend, and the yield acceleration increases by increasing the values of $\phi$ and $K$. In addition, the use of equivalent linear analysis leads to a lower and, therefore, more critical yield acceleration.

Figure 8 presents an examination of the effects of the normalized frequency $\left(\omega H / V_{s 0}\right)$ on the yield acceleration for different values of soil friction angle, $K=0.4$, and for the slope angles of $50^{\circ}$ and $70^{\circ}$. Results in this figure are obtained using the MPD-L and MPD-EL methods by assuming the log-spiral sliding surface. As seen, unlike 

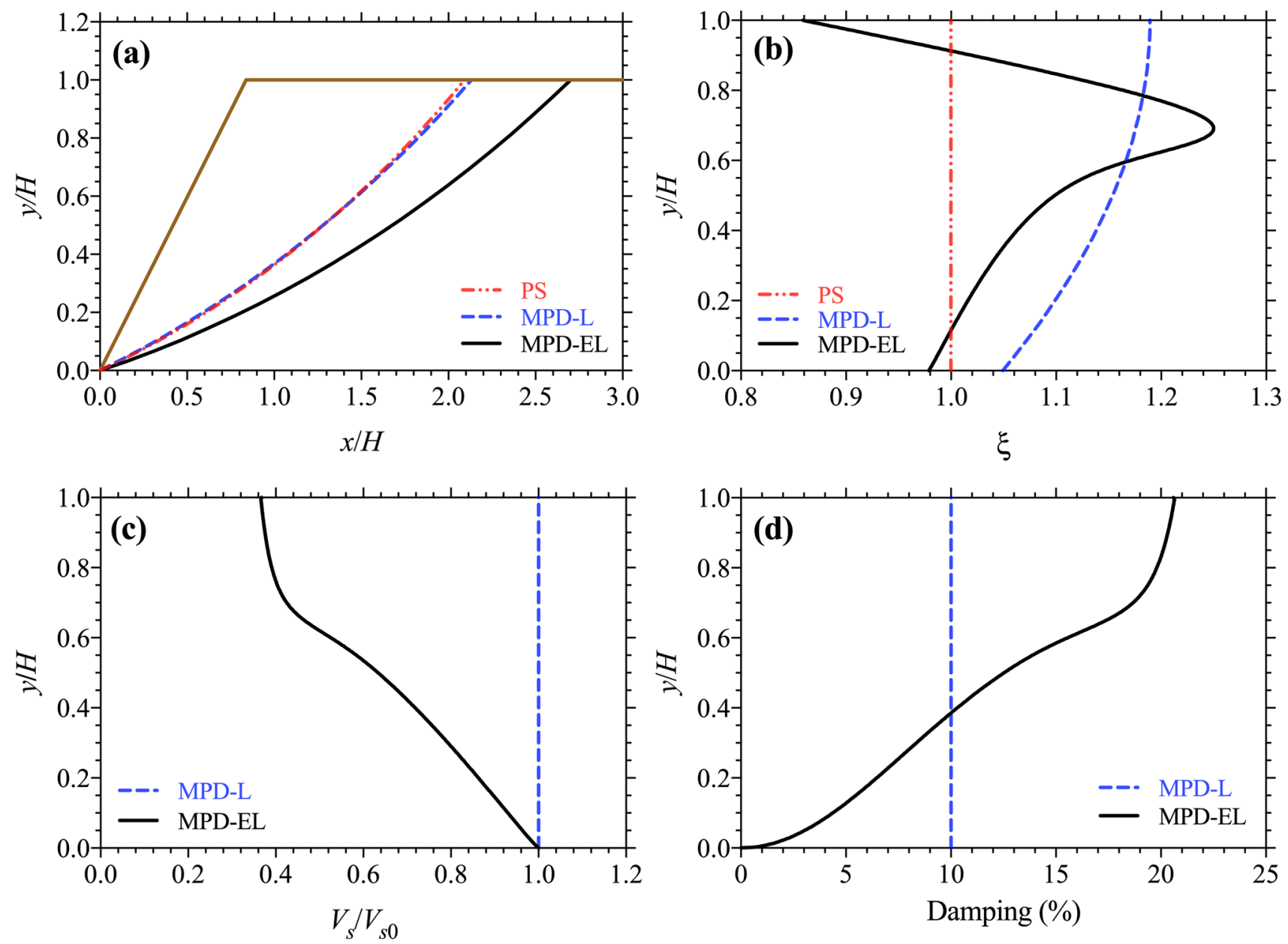

Fig. 10 For $\beta=50^{\circ}, \phi=35^{\circ}, \omega H / V_{s 0}=0.57, K=0.4, T_{\mathrm{u}}<T_{\mathrm{p}^{\prime}}$ and log-spiral slip surface: a optimum slip surface, $\mathbf{b}$ distribution of $\xi$, $\mathbf{c}$ distribution of $V_{\mathrm{s}} / V_{\mathrm{s} 0}$, and $\mathbf{d}$ distribution of damping ratio

the PS method, the yield acceleration is a function of normalized frequency. Furthermore, the yield acceleration decreases up to a threshold $\omega H / V_{\mathrm{s} 0}=1.5$ and then increases again. It is worth noting that this threshold value of the normalized frequency is equal to the fundamental frequency obtained from the 1D ground response analysis. As a result, the least yield acceleration is obtained at this frequency.
Figure 9 compares the values of $K_{y}$ versus $\phi$ obtained from the linear and equivalent linear site response analyses assuming a certain length of reinforcements and both the planar and log-spiral slip surfaces for $L_{\mathrm{r}}=5 \mathrm{~m}, T_{\mathrm{u}}=25$ $\mathrm{kN} / \mathrm{m}, \omega H / V_{\mathrm{s} 0}=0.5$, and uniform distribution of reinforcements. As shown in this figure, the MPD-L method assuming the planar sliding surface produces the largest results, and the MPD-EL method assuming the log-spiral sliding 

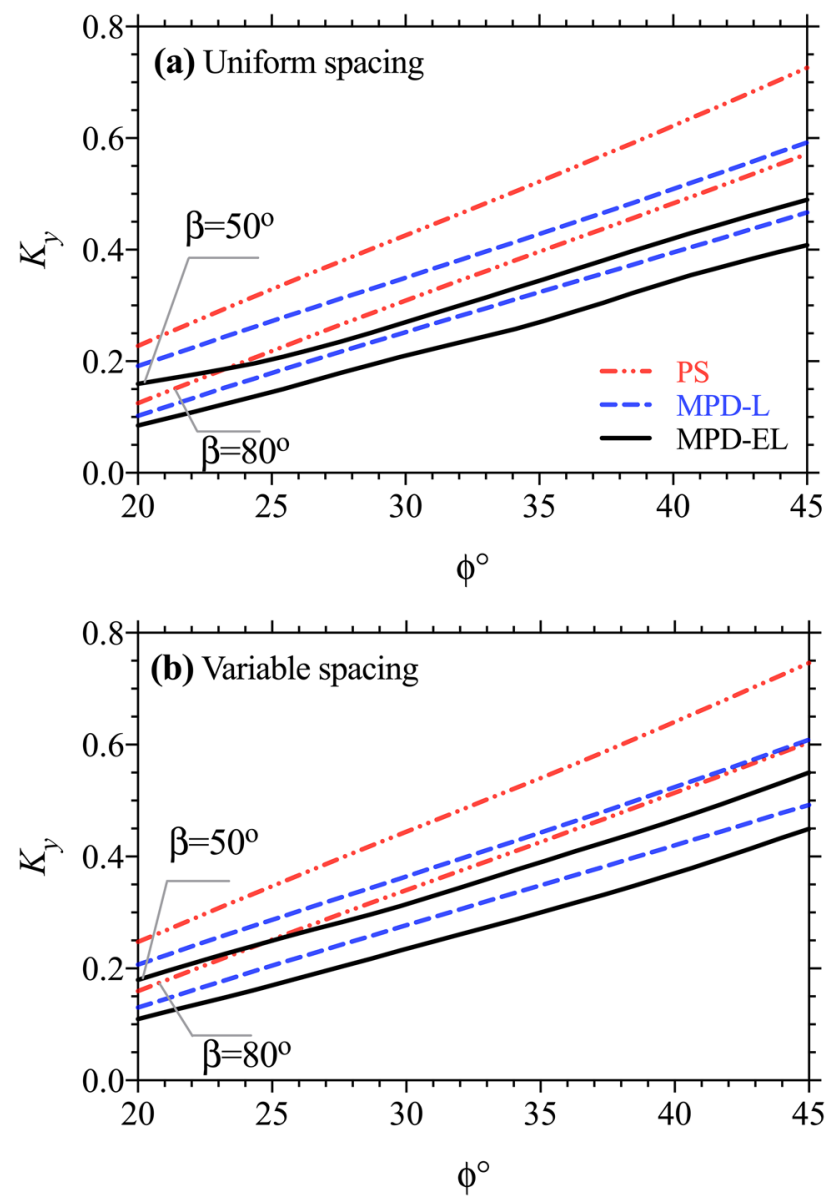

Fig. 11 For $K=0.5, T_{\mathrm{u}}<T_{\mathrm{p}}, \omega H / V_{\mathrm{s} 0}=0.7, \mathrm{D}=15 \%$ (in MPD-L method), and the slope angles of $50^{\circ}$ and $80^{\circ}$; the variations of $K_{y}$ versus $\phi$ obtained from the PS, MPD-L, and MPD-EL methods for a uniform, and $\mathbf{b}$ variable spacing of reinforcements

surface leads to the most conservative values of $K_{\mathrm{y}}$. Figure 9 indicates that the results obtained from the MPDEL method for both planar and log-spiral sliding surfaces are more critical than those computed from the MPD-L method. In addition, this figure shows that using the logspiral failure surface leads to more critical values than that of the planar failure surface.
In Fig. 10, a soil slope is analyzed using PS, MPD$L$, and MPD-EL methods by assuming $\beta=50^{\circ}, \phi=35^{\circ}$, $\omega H / V_{s 0}=0.57, K=0.4, T_{\mathrm{u}}>T_{\mathrm{p}}, D=10 \%$ (in MPD-L method), and log-spiral sliding surface. The yield acceleration values obtained by the PS, MPD-L, and MPD-EL methods are 0.46 , 0.42 , and 0.36 , respectively. Figure 10 a shows the optimum failure surfaces obtained from all three methods. As seen, the failure surface obtained from the MPD-EL method involves a greater volume of soil under the failure condition. Figure $10 \mathrm{~b}$ presents the distribution of the parameter $\xi$ for the three aforementioned analyses versus normalized depth $(y / H)$. According to this figure, unlike the pseudodynamic methods, the acceleration is depth-independent and constant in the pseudo-static method and is not a function of depth and time. Figure 10c and d show the distributions of the shear wave velocity and soil damping ratio, respectively. As shown in these figures, the values of shear wave velocity and soil damping ratio are constant and independent of depth in the MPD-L method.

Figure 11 indicates the effects of reinforcements distribution on the yield acceleration $K_{\mathrm{y}}$ for different values of soil friction angle assuming $K=0.5, \omega H / V_{s 0}=0.7, T_{\mathrm{u}}<T_{p^{\prime}}$ and the slope angle of $50^{\circ}$ and $80^{\circ}$, using PS, MPD-L, and MPD-EL methods. As seen, uniform spacing of reinforcement leads to more critical values of $K_{y}$ compared to the variable spacing.

Figure 12 indicates the effect of the surcharge pressure (q) on $K_{y}$ for various values of soil friction angle assuming $K=0.9, \omega H / V_{\mathrm{s} 0}=0.46, T_{\mathrm{u}}<T_{\mathrm{p}}$, the slope angles of $45^{\circ}$, $60^{\circ}, 75^{\circ}$, and $90^{\circ}, L_{0}=1 \mathrm{~m}, L_{\mathrm{q}}=1 \mathrm{~m}$, by considering uniform spacing of reinforcements using MPD-EL method. This figure indicates that a higher value of surcharge pressure and lower value of soil friction angle cause a lower amount of yield acceleration. As shown in Fig. 12, in many cases, this trend is approximately linear. Note that if the surcharge pressure on the ground surface is considered in the analysis, then in the MPD method, the shear stress boundary condition may not be satisfied at the ground surface. 

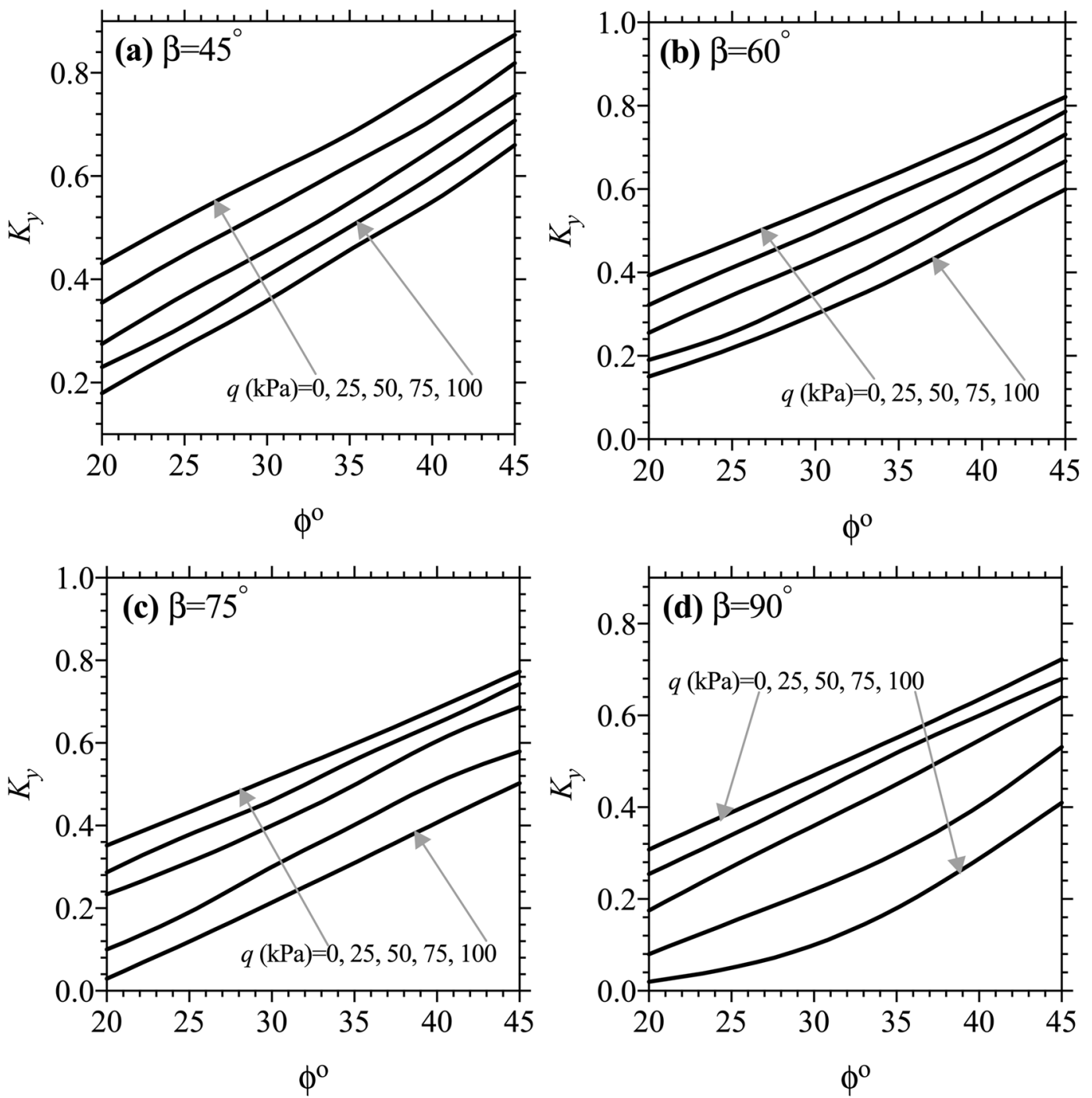

Fig. 12 For $K=0.9, T_{\mathrm{u}}<T_{\mathrm{p}}$, and $\omega H / V_{\mathrm{s} 0}=0.459$; the impact of the surcharge $(q)$ on the variations of $K_{\mathrm{y}}$ versus $\phi$ for PS, MPD-L, and MPD-EL methods for a $\beta=45^{\circ}, \mathbf{b} \beta=60^{\circ}, \mathbf{c} \beta=75^{\circ}$, and $\mathbf{d} \beta=90^{\circ}$

\section{Conclusions}

In this paper, the yield acceleration coefficient $\left(K_{y}\right)$ of the RSSs was calculated using the horizontal slice method (HSM). The reinforcement distribution along depth was considered both uniform and variable spacing. Based on the proposed methodology, a MATLAB code was developed using pseudo-static (PS) and modified pseudodynamic (MPD) methods. The MPD method in this study was carried out through the linear (MPD-L) and equivalent linear (MPD-EL) site response analyses. The utilized formula for HSM satisfies the equilibrium for the horizontal and vertical forces as well as moments for each slice. The outcomes are presented as tables and graphs for different values of soil friction angle $(\phi)$, slope angle $(\beta)$, dimensionless reinforcement force $(K)$, and normalized frequency $\omega H / V_{s 0}$. Furthermore, the results of the PS method were compared to other studies. A summary of results is as follows:

- $K_{y}$ increases by increasing $\phi$ and decreasing $\beta$ in all methods.

- The results of this study using the PS method are very close to those of other research works.

- The results of the PS method were larger, and the results of the MPD-EL method were more conservative than the others. 
- $K_{y}$ increases with increasing $K$. This increase is greater at larger soil friction angles.

- The normalized frequency has a great effect on the yield acceleration. The most critical yield acceleration was obtained at the normalized frequency of $\pi / 2$, which is the fundamental frequency of the vibration of the soil profile in 1-D site response analysis.

- The assumed variable spacing of reinforcements leads to higher values of yield acceleration relative to the uniform spacing.

\section{Compliance with ethical standards}

Conflict of interest The authors declare that they have no competing interests.

\section{References}

1. Lo SCR, Xu DW (1992) A strain-based design method for the collapse limit state of reinforced soil walls or slopes. Can Geotech J 29:832-842. https://doi.org/10.1139/t92-090

2. Shahgholi M, Fakher A, Jones CJFP (2001) Horizontal slice method of analysis. Géotechnique 51:881-885. https://doi. org/10.1680/geot.2001.51.10.881

3. Fakher A, Nouri H, Shahgholi M (2002) Limit equilibrium in reinforced soil walls subjected to seismic loads. In: Proceeding of the third Iranian conference on geotechnical engineering and soil mechanics, pp 281-286

4. Nouri H, Fakher A, Jones CJFP (2006) Development of horizontal slice method for seismic stability analysis of reinforced slopes and walls. Geotext Geomembr 24:175-187. https://doi. org/10.1016/j.geotexmem.2005.11.004

5. Azad A, Yasrobi SS, Pak A (2008) Seismic active pressure distribution history behind rigid retaining walls. Soil Dyn Earthq Eng 28:365-375. https://doi.org/10.1016/J.SOILDYN.2007.07.003

6. Reddy GVN, Madhav MR, Reddy ES (2008) Pseudo-static seismic analysis of reinforced soil wall: effect of oblique displacement. Geotext Geomembranes 26:393-403. https://doi.org/10.1016/j. geotexmem.2008.02.002

7. Bathurst RJ, Cai Z (1995) Pseudo-static seismic analysis of geosynthetic reinforced segmental retaining walls. Geosynth Int 2:787-830. https://doi.org/10.1680/gein.2.0037

8. Ling HI, Leshchinsky D, Perry EB (1997) Seismic design and performance of geosynthetic-reinforced soil structures. Geotechnique 47:933-952. https://doi.org/10.1680/geot.1997.47.5.933

9. Michalowski RL (1997) Stability of uniformly reinforced slopes. J Geotech Geoenviron Eng 123:546-556. https://doi. org/10.1061/(ASCE)1090-0241(1997)123:6(546)

10. Michalowski RL (1998) Soil reinforcement for seismic design of geotechnical structures. Comput Geotech 23:1-17. https:// doi.org/10.1016/S0266-352X(98)00016-0

11. Ausilio E, Conte E, Dente G (2000) Seismic stability analysis of reinforced slopes. Soil Dyn Earthq Eng 19:159-172. https:// doi.org/10.1016/S0267-7261(00)00005-1

12. Ghanbari A, Khalilpasha A, Sabermahani M, Heydari B (2013) An analytical technique for estimation of seismic displacements in reinforced slopes based on horizontal slices method (HSM). Geomech Eng 5:143-164. https://doi. org/10.12989/gae.2013.5.2.143

13. Khosravizadeh $M$, Dehestani M, Kalantary F (2016) On the seismic stability and critical slip surface of reinforced slopes. Soil Dyn Earthq Eng 85:179-190. https://doi.org/10.1016/j.soild yn.2016.03.018

14. Pakdel P, Jamshidi Chenari R, Veiskarami M (2019) Seismic bearing capacity of shallow foundations rested on anisotropic deposits. Int J Geotech Eng. https://doi.org/10.1080/19386 362.2019.1655983

15. Izadi A, Nazemi Sabet Soumehsaraei M, Jamshidi Chenari R, Ghorbani A (2019) Pseudo-static bearing capacity of shallow foundations on heterogeneous marine deposits using limit equilibrium method. Mar Georesour Geotechnol 37:11631174. https://doi.org/10.1080/1064119X.2018.1539535

16. Vahedifard F, Leshchinsky D, Meehan CL (2012) Relationship between the seismic coefficient and the unfactored geosynthetic force in reinforced earth structures. J Geotech Geoenviron Eng 138:1209-1221. https://doi.org/10.1061/(ASCE) GT.1943-5606.0000701

17. Bellezza I (2015) Seismic active earth pressure on walls using a new pseudo-dynamic approach. Geotech Geol Eng 33:795812. https://doi.org/10.1007/s10706-015-9860-1

18. Bellezza I (2014) A new pseudo-dynamic approach for seismic active soil thrust. Geotech Geol Eng 32:561-576. https://doi. org/10.1007/s10706-014-9734-y

19. Pain A, Choudhury D, Bhattacharyya SK (2017) Seismic rotational stability of gravity retaining walls by modified pseudodynamic method. Soil Dyn Earthq Eng 94:244-253. https:// doi.org/10.1016/j.soildyn.2017.01.016

20. Pain A, Choudhury D, Bhattacharyya SK (2017) Seismic passive earth resistance using modified pseudo-dynamic method. Earthq Eng Eng Vib 16:263-274. https://doi.org/10.1007/ s11803-017-0381-1

21. Pain A, Choudhury D, Bhattacharyya SK (2015) Seismic stability of retaining wall-soil sliding interaction using modified pseudo-dynamic method. Geotech Lett 5:56-61. https://doi. org/10.1680/geolett.14.00116

22. Chanda N, Ghosh S, Pal M et al (2017) Analysis of slope using modified pseudo-dynamic method. Int J Geotech Eng. https ://doi.org/10.1080/19386362.2016.1277848

23. Pain A, Choudhury D, Bhattacharyya SK (2017) Effect of dynamic soil properties and frequency content of harmonic excitation on the internal stability of reinforced soil retaining structure. Geotext Geomembr 45:471-486. https://doi. org/10.1016/j.geotexmem.2017.07.003

24. Keshavarz A, Abbasi $H$, Fazeli A (2020) Yield acceleration of reinforced soil slopes. Int J Geotech Eng 14:80-89. https://doi. org/10.1080/19386362.2017.1404736

25. Izadi A, Nazemi Sabet Soumehsaraei M, Jamshidi Chenari R et al (2019) Spectral bearing capacity analysis of strip footings under pseudo-dynamic excitation. Geomech Geoeng. https:// doi.org/10.1080/17486025.2019.1670873

26. Saha A, Ghosh S (2019) Modified pseudo-dynamic bearing capacity of shallow strip footing considering fully log-spiral passive zone with global center. Iran J Sci Technol Trans Civ Eng. https://doi.org/10.1007/s40996-019-00271-1

27. Pain A, Choudhury D, Bhattacharyya SK (2016) The seismic bearing capacity factor for surface strip footings. In: Geotechnical special publication. American Society of Civil Engineers (ASCE), pp 197-206. https://doi.org/10.1061/9780784480120.021

28. Saha A, Ghosh S (2020) Modified pseudo-dynamic bearing capacity analysis of shallow strip footing considering total 
seismic wave. Int J Geotech Eng 14:101-109. https://doi. org/10.1080/19386362.2017.1405542

29. Price VE, Morgenstern NR (1968) The analysis of the stability of general slip surfaces. Géotechnique 18:393-394. https://doi. org/10.1680/geot.1968.18.3.393

30. Seed HB, Idriss IM (1970) Soil moduli and damping factors for dynamic response analyses. Report no. EERC 70e10. Earthquake
Engineering Research Center, University of California, Berkeley, California

Publisher's Note Springer Nature remains neutral with regard to jurisdictional claims in published maps and institutional affiliations. 